\title{
The 2008 Presidential Primaries through the Lens of Prediction Markets
}

\section{(Research Note)}

\author{
Neil Malhotra \\ Stanford Graduate School of Business \\ neilm@stanford.edu \\ Erik Snowberg \\ California Institute of Technology \\ snowberg@caltech.edu
}

\begin{abstract}
To explore the influence of primary and caucus results during the 2008 nomination process we leverage a previously unused methodology - the analysis of prediction market contracts. The unique structure of prediction markets allows us to address two questions. First, we analyze whether primary and caucus results affect candidates' chances in the general election, as candidates who take extreme positions during the nomination contest may be unable to easily appeal to centrist voters in the general election. We also assess whether states with early primaries, such as Iowa and New Hampshire, have a disproportionate effect on the nominating process. We show that the length of the primary process has a minimal impact of the electability of candidates in the general election, and that some states have a disproportionate impact on the nominating process. However, the states that have the largest impact are not necessarily New Hampshire and Iowa, the two that have often been assumed to be the most influential because of their early position on the primary calendar.
\end{abstract}


The 2008 primary process was extraordinary for its length, the movement of contests earlier on the calendar, and the high level of voter participation (Tolbert and Squire 2009). Yet, scholars and commentators were concerned in 2008 , as in previous elections, with how the nomination process would affect candidates' general election prospects and whether some states exerted disproportionate influence on the final outcome. In this sense, it was also quite ordinary. We leverage another way in which 2008 was exceptional — the existence of liquid prediction markets following each candidate and nominating contest—-to explore these concerns in a straightforward, novel way that would be extremely difficult without prediction market contracts.

We first examine whether primaries and caucuses damage a candidate's electoral viability in the general election, a question that has received limited empirical attention. ${ }^{1}$ The primary process may constrain candidates from converging to the position of the median voter, as they will take on more extreme positions to satisfy (non-strategic) primary voters who are less moderate than the general population (Geer 1988; Grofman 1993; Norrander 1989). Thus, in a spatial model, a primary process will damage the general election prospects of candidates. By using prediction markets to calculate a candidate's chance of winning the general election conditional on winning his or her party's nomination, we show that the results of individual contests have at best a small impact on candidate's general election chances. ${ }^{2}$

States early in the primary process are presumed to have a disproportionate effect through building candidate viability, attracting donors and volunteers, and creating momentum (e.g.

\footnotetext{
${ }^{1}$ A significant amount of literature has focused on the general election impacts of divisive nominating contests (e.g. Buell 1986; Stone, Atkenson, and Rapoport 1992; Kenney and Rice 1987). Whereas the previous literature has mainly focused on whether supporters of defeated candidates in the nomination contest "come home" to vote for their party's nominee in the general election, we study the effects of early contests more broadly, including candidates' difficulties of returning to the center in the general after trying to attract primary voters.

${ }^{2}$ In line with our results Norpoth (2004) uses the results of the New Hampshire primary to predict general election vote share for each possible match-up of Democratic and Republican candidates. An underlying assumption of Norpoth's model is that other contests do not have an effect on the general election vote share of candidates. Of course, it may be the case that individual contests do not have an effect on candidate chances in the general election, but the system itself does.
} 
Abramowitz 1989; Abramson et al. 1992; Mutz 1998). Theoretical work demonstrates that voters can use early contests as cues in determining their vote choices (e.g. Morton and Williams 2001; Callender 2007; Serra, 2007; Ali and Kartik 2008). The bulk of the empirical literature on this subject analyzes public opinion polling and survey data (Bartels 1988; Johnson et al. 1992), campaign contributions (Mutz 1995), future election results (Hinckley and Green 1996; Adkins and Dowdle 2001; Steger 2007), and laboratory experiments (Morton and Williams 2001; Rickershauser and Aldrich 2007). Normatively, unequal influence may be problematic as states with early contests are demographically unrepresentative of the U.S. ${ }^{3}$

We assess whether states with early primaries, such as Iowa and New Hampshire, have an effect on the nominating process that is disproportionate to their small number of delegates. We use prediction markets to compute the impact of a state's contest on the chances of a given candidate winning his or her party's nomination, and compare that figure to the number of delegates allotted to that state. The continuous updating of prediction markets to events allows us to precisely estimate the effect of each contest. In 2008, earlier states appeared to be more important. South Carolina and Nevada had the biggest impact on the Republican nomination, whereas Louisiana, Nebraska, and Washington had largest influence on the Democratic nomination. The delegate-rich Super Tuesday states had a disproportionately small impact.

\section{Prediction Markets}

Prediction markets are contracts whose payoffs are contingent on events. In their simplest form, used here, they pay $\$ 1$ if a certain candidate wins an election, and nothing

\footnotetext{
${ }^{3}$ See Beckel and Thomas (2008), Hallett, Torry, and Rowland (2007), and Hickey, Myers, and Theriault (2008). Conversely, Lewis-Beck and Squire (2009) argue that Iowa is reasonably representative of the U.S. Aside from this debate on demographics, the caucus process in Iowa is certainly not representative of nominating processes elsewhere. We do not take a stance on whether or not this is normatively problematic.
} 
otherwise (see Wolfers and Zitzewitz 2004 for an overview). Maintaining the efficient markets hypothesis, as we do throughout, the price of the contract at any time is interpretable as the probability that the candidate will win the election (Wolfers and Zitzewitz 2006). Prediction markets are generally better predictors of election outcomes than polls, and have the added advantage of updating continuously based on current events. ${ }^{4}$ In political science, prediction markets are largely used to study the effects of elections on the economy (e.g.: Herron 2000; Knight 2006; Snowberg et al. 2007a, b; Fowler 2008; Mattozzi 2008).

The prediction market data in this paper come from several markets run on Intrade.com. We use markets that track the probability that each candidate wins each nominating contest, the probability that each candidate wins his or her party's nomination, and the probability that a candidate wins the general election. Data from these markets can be combined to derive the candidate's chance of general election victory conditional on nomination, as well as the influence of each contest on the party's nomination.

\section{How Do Primary and Caucus Outcomes Affect Expectations About the General Election?}

We first examine whether the outcomes of the 2008 nominating contests affect the electoral prospects of candidates in the general election. As mentioned above, the electorates of primary contests and general elections are quite different, and success in attracting the support of strong partisans in the primary process may come at the cost of diminished support among centrist voters in November. This will be particularly true if candidates are constrained by positions they take early in the nominating campaign.

\footnotetext{
${ }^{4}$ See Wolfers and Zitzewitz (2004) for an overview. Contrary to these findings, Erikson and Wlezian (2008) find that adjusted polls provide a better predictor than raw prediction market prices, while Rothschild (2009) applies a similar transformation to both polls and prediction markets, and finds that adjusted prediction markets provide better predictions in contested elections than adjusted polls. See Snowberg et al. (2005) for some potential weaknesses of prediction markets.
} 
Prediction markets can be used to estimate $P(G \mid N)$, a candidate's probability of winning the general election conditional on winning the nomination. By definition,

$$
P(G \mid N)=\frac{P(G \cap N)}{P(N)},
$$

where $P(G \cap N)$ is the probability of the candidate winning the general election and the nomination and $P(N)$ is the probability of the candidate winning the nomination. If a candidate wins the general election, he or she must have won the nomination, so $P(G \cap N)=P(G)$. Thus,

$$
P(G \mid N)=\frac{P(G)}{P(N)}
$$

The conditional probability of winning the general given that the candidate has won the nomination is the ratio of the probability of winning the general to the probability of winning the nomination. Prediction markets measure both of these quantities.

It would be very difficult to derive $P(G \mid N)$ using data from public opinion polls. An analyst would need general election polls, head-to-head polls between all of the Democratic and Republican candidates and polling data that would allow him or her to determine the probability of each candidate winning the nomination. Much of this data is rarely, if ever, available.

In the analysis that follows, we examine the change in the probability of winning the general election conditional on winning the nomination before and after each contest for each party. ${ }^{5}$ To do so, we recorded prices of contracts tied to candidates winning the general election and the nomination (i.e., $P(G)$ and $P(N)$, respectively) every ten minutes on the day before and

\footnotetext{
${ }^{5}$ When there are two contests (i.e. a primary and a caucus) in a single state, we focus on the one yielding the highest number of delegates.
} 
the day after a primary or caucus, We took the mean of the bid and ask prices and then computed a mean for each day. Finally, we use (2) to calculate $P(G \mid N){ }^{6}$

Table 1 presents the results for each Democratic contest. The first two columns list the contest dates and all of the states that had primaries and/or caucuses on those dates. The next three columns present the change in the conditional probabilities of Barack Obama, Hillary Clinton, and John Edwards winning the general election given that they win the nomination. For reference, the final column lists the change in the prediction market contract of a Democrat — any Democrat - winning the general election.

The key finding is that primary contests have little impact on candidates' chances of winning the general election. For both Obama and Clinton, no day of primaries and/or caucuses changed their conditional probabilities by more than 10 percentage points; the average change is 1.06 percentage points. This indicates that, on average, each contest increased the probability of a Clinton or Obama (or more generally, Democratic) victory in the general election. ${ }^{7}$

Primaries that were extremely likely to have lengthened the Democratic nomination process (IA, NH, and $\mathrm{OH} / \mathrm{TX}$ ) have a slight negative effect on candidates' conditional probabilities. ${ }^{8}$ Clinton's narrow wins in Ohio and Texas, which extended the primary process by two months, as she was expected to win Pennsylvania a month later, decreased Obama's conditional probability by 3 percentage points. This translates into an expected vote share loss of

\footnotetext{
${ }^{6}$ We also calculated standard errors for all quantities. All of the figures below are highly statistically significantly different from zero. For simplicity we report point estimates without standard errors.

${ }^{7}$ Many of the largest changes in conditional probabilities are when a candidate had very little chance of winning the nomination. Thus, a relatively small change in the candidate winning the nomination, $P(N)$, results in a large change in the conditional probability.

${ }^{8}$ We judge any contest where the candidate who was behind increased their probability of winning the nomination by 10 percentage points (in Table 3 ) as one that lengthened the primary process.
} 
less than 0.4 percentage points in the general election. ${ }^{9}$ Three percentage points is smaller than the boost Kerry received for his unexpectedly strong performance in the first debate of the 2004 presidential election, or the one Obama received from the bankruptcy of Lehman Brothers. ${ }^{10}$

What are the implications of these results for the study of presidential primaries? There are three effects to consider: a longer primary process may commit a candidate to unpopular positions (as discussed above), "bloody" primaries may exhaust a candidates resources, or a longer primary process may benefit a candidate by giving him or her greater visibility, resources, and experience. Our results show that if there are negative effects of a longer primary process they are quite small, or outweighed by the positive effect of greater experience and attention. It appears that primaries do not significantly constrain a candidate from moving towards the center once he or she has secured the nomination, or that countervailing factors offset any constraint.

Several other data points in Table 1 conform to the standard narrative of the 2008 primaries. Obama's conditional probability showed its largest increase (4.5 percentage points), and Clinton's conditional probability its largest decrease (5.7 percentage points), following the South Carolina primary. Many pundits consider, Obama's resounding victory a turning point in the race that may have signaled the consolidation of his support among African-Americans.

Moreover, Clinton's greatest conditional probability gains were achieved after the Indiana and North Carolina contests on May 6, and the Kentucky and Oregon contests on May 20. These contests demonstrated her strength among white, working-class Democrats. This,

\footnotetext{
${ }^{9}$ This figure is derived from an underlying vote share distribution. Assume this distribution is normal, and that Obama's initial conditional probability of victory was 50\% (this simplifies the math, but the result is similar using the real figure of $\sim 51.5 \%$ ). Finding Obama's expected vote share after the contest involved solving for $\mu$ s.t.

$$
\frac{1}{2} \operatorname{erf}\left(\frac{0.50-\mu}{\sigma \sqrt{2}}\right)=0.03
$$

which depends on $\sigma$, the standard deviation of the vote share distribution. Assuming a conservative 5\% $(0.05)$ standard deviation implies a change in expected vote share of 0.376 percentage points, from $50 \%$ to $\sim 49.6 \%$.

${ }^{10}$ These increases are estimated from other Intrade prediction market contracts.
} 
coupled with the perceived importance of these voters in the general election may have increased her probability of winning the general election conditional on the increasingly unlikely chance of her securing the nomination.

Analogous results for the Republican primaries can be found in Table 2. For McCain, the eventual nominee, there is great stability in conditional probabilities over time. This underscores that primaries have a relatively small influence on general election prospects. Additionally, because McCain had largely secured the nomination following Super Tuesday, the subsequent primaries were, for all practical purposes, not covered by the media nor strongly contested, thereby minimizing their impact on McCain's general election prospects (Cooper 2008). One interesting departure is February 9 (four days after Super Tuesday), where Huckabee performed extremely well in Louisiana and Kansas. This was perceived to be a sign of protest by conservative Republicans against the impending McCain nomination, potentially explaining the drop in McCain's conditional probability of winning the general election.

The volatile changes of McCain's two less viable rivals are interesting. Huckabee's general election prospects increased substantially after Florida (perhaps due to the simultaneous harm that contest did to the Giuliani, Thompson, and Romney candidacies - all of whom had bet heavily on performing well in Florida). Romney, on the other hand, consistently saw improvements in his conditional probability, driven a growing sense of his electability among general election voters.

\section{The Disproportionate Influence of Early Nominating Contests}

It has long been surmised that states early in the nominating calendar (e.g. Iowa and New Hampshire) have disproportionate influence in determining the parties' nominees. Their early 
positions allow victorious candidates (or at least candidates who perform "better than expected") to build momentum and attract undecided voters, donors, volunteers, and media coverage. As noted in the introduction, this has been studied in a variety of ways.

Prediction markets offer a new way of assessing the impact of early primaries and caucuses. For each contest we assess the resulting change in the probability of a candidate winning the nomination and compare it to the number of delegates awarded. Note that it would be extremely difficult to derive changes in the probability of nomination from public opinion polls. An analyst would need polling data on the subset of the American population that has not yet participated in the primaries. Moreover, polls do not tell us who is most likely to win the nomination, given the complicated procedures involved in assigning delegates. Conversely, prediction market contracts are traded consistently each day, and price in the nuances of the nominating process.

In Table 3, we present the changes in contracts tied to specific contest outcomes for the two Democratic candidates who competed in all races (Obama and Clinton) in both absolute terms (i.e., signed change in price of the contract between the day before the contest date and the day after) and percentage terms (i.e., percent increase or decrease in the price of the contract one day before and one day after the contest). ${ }^{11}$ In the final column of Table 3, we list the number of voting delegates at the Democratic National Convention awarded in these contests.

In order to fairly compare the importance of contests, we need to account for the fact that some were hotly contested, whereas others were near certainties. We would like to compare the change in a candidates' chance of obtaining the nomination due to winning, rather than losing, a given contest. However, we do not observe the effects of the candidate both winning and losing

\footnotetext{
${ }^{11}$ We exclude Edwards because he dropped out of the race prior to Super Tuesday, and therefore do not have usable contract prices for the full set of states. Additionally, due to lack of data, we exclude U.S. territories.
} 
the same contest. Instead we observe the probability that a candidate would win the contest the day before, and the probability the day after (which is either 0 or 1 ). Thus, in the case of the Iowa caucus where Obama had a $46 \%$ chance of winning the day before, he only "won" $54 \%$ of that contest on caucus night. But we are interested in the effect of winning all (100\%) of the contest. To adjust for this, the fifth and sixth columns of Table 3 report

$$
\frac{\text { abs. change }}{I(\text { win })-p}
$$

where $I$ (win) is an indicator that takes on a value of ' 1 'if a candidate won the contest, and ' 0 ' otherwise, and $p$ is the expected probability the candidate wins the contest the day before. ${ }^{12}$ Due to the unreliability of extremely large or small contract prices, we do not calculate an adjusted figure when the denominator of (4) is less than $5 \%{ }^{13}$

Consistent with popular consensus and scholarly work (e.g. Bartels 1988), Iowa and New Hampshire had a larger influence in 2008 than would be expected based on the number of delegates apportioned to these contests. As shown in Table 3 and Figure 1, these two states together comprise $2 \%$ of the total number of delegates yet they had half the effect of Super Tuesday, where $49 \%$ of the delegates were up for grabs. Interestingly, Iowa and New Hampshire are not the most influential contests. Rather, the first contests after Super Tuesday (Louisiana, Nebraska, and Washington) had a larger impact. This marked the beginning of Obama's string of victories following the even results of Super Tuesday, affirming him as the frontrunner for the nomination. The importance of these particular contests is likely to be unique to 2008 .

\footnotetext{
${ }^{12}$ For example, prediction markets showed that Clinton had a $\sim 10 \%$ chance of winning the New Hampshire primary the night before. Since Clinton actually did win the contest, we divide the change in her nomination contact by 0.9 . On the other hand, Clinton won the Ohio primary, which she had a nearly $70 \%$ chance of winning the night before. Thus, we divide by 0.3 . For Obama, who had an approximately $30 \%$ chance of winning, we divide by -0.3 .

${ }^{13}$ The favorite-longshot bias (Snowberg and Wolfers, 2007), where prices diverge from underlying probabilities when prices are close to zero or one, makes these numbers unreliable, and also invalidates the linear scaling we implicitly assume in (4). For more on adjustments like those in (4), see Snowberg et al. (2007a).
} 
The results, shown in Table 4 and Figure 2, are somewhat similar for the Republican contests, in which McCain was the only candidate to remain throughout all primaries and caucuses. Again, Super Tuesday, where $46 \%$ of Republican delegates were awarded, had a proportionately small impact on McCain's probability of nomination. The effect is in line with single states that held their contests on their own day, such as Florida. However, the most important states on the Republican calendar were Nevada and South Carolina, which together apportioned only $2.5 \%$ of the Republican delegates. In the latter state, McCain scored a solid victory over Huckabee, demonstrating his appeal to Southern conservative voters. Finally, after McCain became the presumptive nominee following Super Tuesday, the subsequent contests, unsurprisingly, had little effect on contract prices. ${ }^{14}$

Overall, in 2008 New Hampshire and Iowa had a disproportionate effect on the nomination contest in both parties. In line with Steger et. al. (2004), which analyzes polling data, we find that New Hampshire had a smaller effect for Republicans than Democrats. However, there were other contests that were both more important, and had a more disproportionate impact. This may have been unique to 2008 as several states advanced their contest dates to be closer to Iowa and New Hampshire, thereby diminishing the influence of the "first-in-the-nation" states. Additionally, the expectation that the nomination would be closely fought between Obama and Clinton may have contributed to lower-than-usual leverage for Iowa and New Hampshire. Finally, although Super Tuesday had a large impact, it was much smaller than the proportion of

\footnotetext{
${ }^{14}$ We model the relationship between the change in the probability of Obama (or McCain) gaining their respective nomination as follows: $\Delta($ Probability of Nomination $)=\alpha+\beta_{1} * \Delta($ time $)+\beta_{2} *$ delegates $+\varepsilon$

For both parties we find a negative and marginally statistically significant relationship between the change in the probability of nomination and the time since the Iowa caucus ( $\Delta$ time), and a positive but insignificant relationship between the change in the probability of nomination and the number of delegates a state has (results available by request). This suggests that having an early date on the nominating calendar increased the influence of a contest, reinforcing the findings above. Due to the small sample size, these results should be interpreted cautiously.
} 
delegates awarded. Perhaps the bundling of several large states on a single day minimizes the impact of each individual state. In 2008, it appeared advantageous for states to seek out unique spots on the calendar, even if that meant going later than other states.

\section{Conclusion}

Using prediction markets tied to the 2008 presidential nominating contests and general election, we have shown that the length of the nomination season has a minimal impact on the electability of candidates in the general, and that certain states have a disproportionate impact on the nominating process. However, the states that have the largest impact are not necessarily New Hampshire and Iowa, the two which have often been assumed to be the most influential. Indeed, the states with the largest impacts were idiosyncratic and specific to each party.

This reinforces the main weakness of this paper-namely that we use data only from a single election year. Our results can only apply to other elections to the extent that 2008 is typical of a presidential election year. Although many commentators (e.g. Pew 2008) have been quick to point out the differences between 2008 and a typical election year (whatever that is), by using prediction markets to study the questions addressed here over time, it may be possible to asses in a more rigorous way just how typical or atypical the 2008 election was. 


\section{References}

Abramowitz, Alan I. "Viability, Electability, and Candidate Choice in a Presidential Primary Election: A Test of Competing Models." The Journal of Politics 51 (1989): 977-92.

Abramson, Paul R., John H. Aldrich, Phil Paolino, and David Rohde. "Sophisticated Voting in the 1988 Presidential Primaries." American Political Science Review 86 (1992): 55-69.

Adkins, Randall E., and Andrew J. Dowdle. "How Important Are Iowa and New Hampshire to Winning Post-Reform Presidential Nominations." Political Research Quarterly 54 (2001): 431-44.

Ali, S. Nageeb and Navin Kartik. "Social Learning in Elections." Working Paper: University of California, San Diego, 2008.

Bartels, Larry M. Presidential Primaries and the Dynamics of Public Choice. New York: Princeton University Press, 1988.

Beckel, Bob, and Cal Thomas. "Does Your Vote Matter?" USA Today 10 Jan. 2008: 9A.

Buell, Emmett H., Jr. "Divisive Primaries and Participation in Fall Presidential Campaigns: A Study of 1984 New Hampshire Primary Activists.” American Politics Quarterly 14 (1986): 376-90.

Callander, Steven. "Bandwagons and Momentum in Sequential Voting." The Review of Economic Studies 74 (2007): 653-84.

Cooper, Michael. "McCain wins big on Super Tuesday." International Herald Tribune 6 Feb. 2008.

Donavan, Todd and Rob Hunsaker. "Beyond Expectations: Effects of Early Elections in U.S. Presidential Nomination Contests." PS: Political Science and Politics 42 (2009): 45-52. 
Fowler, James H. "Elections and Markets: The Effect of Partisanship, Policy risk, and Electoral Margins on the Economy.” The Journal of Politics 68 (2008): 89-103.

Geer, John. "Assesing the Representativeness of Electorates in Presidential Primaries." American Journal of Political Science 32 (1988): 927-43.

Grofman, Bernard. "Downs and Two-Party Convergence." Annual Review of Political Science 7 (2004): 25-46.

Grofman, Bernard N. Information, Participation, and Choice : An Economic Theory of Democracy in Perspective. New York: University of Michigan P, 1993.

Herron, Michael C. "Estimating the Economic Impact of Political Party Competition in the 1992 British Election. " American Journal of Political Science 44 (2000): 326-337.

Hinckley, Katherine, and John C. Green. "Fund-raising in Presidential Nomination Campaigns: The Primary Lessons of 1988." Political Research Quarterly 49 (1996): 693-718.

Johnston, Richard, Andre Blais, and Henry E. Brady. Letting the People Decide : The Dynamics of a Canadian Election. New York: Stanford UP, 1992.

Kenney, Patrick J., and Tom W. Rice. "The Relationship between Divisive Primaries and General Election Outcomes." American Journal of Political Science 31 (1987): 31-44. Knight, Brian. "Are Policy Platforms Capitalized into Equity Prices? Evidence from the Bush/Gore 2000 Presidential Election.” Journal of Public Economics 90 (2006): 751773.

Lewis-Beck, Michael S. and Peverill Squire. “Iowa: The Most Representative State?” PS: Political Science and Politics 42 (2009): 37-44

Mattozzi, Andrea. "Can We Insure Against Political Uncertainty? Evidence from the U.S. Stock Market. " Public Choice 137 (2008): 43-55. 
Morton, Rebecca B., and Kenneth Williams. Learning by Voting : Sequential Choices in Presidential Primaries and Other Elections. New York: University of Michigan P, 2001. Mutz, Diana. "Effects of Horse-Race Coverage on Campaign Coffers: Strategic Contributing in Presidential Elections." Journal of Politics 57 (1995): 1015-044.

Mutz, Diana C. Impersonal Influence : How Perceptions of Mass Collectives Affect Political Attitudes. New York: Cambridge UP, 1998.

Norrander, Barbara. "Ideological Representativeness of Presidential Primary Voters." American Journal of Political Science 33 (1989): 570-87.

Norpoth, Helmut. "From Primary to General Election: A Forecast of the Presidential Vote.” PS: Political Science and Politics 37 (2004): 737-740.

The Pew Center on the States. 2008 Primary in Review. Washington, DC: The Pew Charitable Trust, 2008.

Rickershauser, Jill, and John Aldrich. "'It's the Electability, Stupid" - Or maybe not? Electability, Substance, and Strategic Voting in Presidential Primaries." Electoral Studies 26 (2007): 371-80.

Rothschild, David. "Forecasting Elections: Transforming Raw Prediction Market Prices and Polls into a Probability of Victory." Working paper: University of Pennsylvania, 2009.

Serra, Gilles. "Why Primaries? The Strategic Chocie of a Candidate Selection Method." American Political Science Association, APSA 2007 Annual Meeting, 31 Oct. 2007. Snowberg, Erik and Justin Wolfers. "Explaining the Favorite-Longshot Bias: Is it Risk-Love or Misperceptions?” Working Paper: California Institute of Technology, 2007. 
Snowberg, Erik, Justin Wolfers and Eric Zitzewitz. "Information (In)Efficiency in Prediction Markets." In Information Efficiency in Betting Markets, Leighton Vaughn Williams, Editor. Cambridge: Cambridge UP, 2005.

Snowberg, Erik, Justin Wolfers and Eric Zitzewitz. "Partisan Impacts on the Economy: Evidence from Prediction Markets and Close Elections.” The Quarterly Journal of Economics 122 (2007a): 807-829.

Snowberg, Erik, Justin Wolfers and Eric Zitzewitz. "Party Influence in Congress and the Economy.” The Quarterly Journal of Political Science 2 (2007b): 277-286.

Steger, Walter P. "Who wins Nominations and Why? An Updated Forecast of the Presidential Primary Vote." Political Research Quarterly 60 (2007): 91-99.

Steger, Walter P., Andrew J. Dowdle and Randall E. Adkins. "The New Hampshire Effect in Presidential Elections.” Political Research Quarterly 57 (2004): 375-390.

Stone, Walter J., Lonna Rae Atkeson, and Ronald B. Rapoport. "Turnout On or Turning Off? Mobilization and Demobilization Effects of Participation in Presidential Nomination Contests." American Journal of Political Science 36 (1992): 665-91.

Theriault, Sean, Hickey Patrick, and Adam Myers. "'First-in-the-Nation in Proficiency or by Providence? Iowa, New Hampshire and the Presidential Primary Process"'" APSA, APSA 2008 Annual Meeting, 28 Aug. 2008, Hynes Convention Center, Boston, MA.

Tolbert, Caroline and Peverill Squire. "Reforming the Presidential Nomination Process." PS: Political Science and Politics 42 (2009): 27-32.

Torry, Jack, Joe Hallett, and Darrel Rowland. "Are Iowa, N.H. Really Worthy?" Columbus Dispatch 30 Dec. 2007.

Wolfers, Justin and Eric Zitzewitz. "Prediction Markets." Journal of Economic Perspectives 18(2004): 107-126. 
Wolfers, Justin and Eric Zitzewitz. "Interpreting Prediction Market Prices as Probabilities." NBER Working Paper \#12200 (2006). 
Table 1: Changes in Probabilities of Winning General Election Conditional on Winning the Nomination (Democrats)

\begin{tabular}{llcccc}
\hline Date & States & Obama & Clinton & Edwards & Democrat \\
$1 / 3$ & IA & $0.3 \%$ & $0.5 \%$ & $-4.3 \%$ & $1.4 \%$ \\
$1 / 8$ & NH & 3.3 & -3.8 & 8.8 & 0.1 \\
$1 / 15$ & MI & 0.4 & -0.7 & 11.5 & 0.1 \\
$1 / 19$ & NV & -0.6 & 0.2 & -8.8 & -0.5 \\
$1 / 26$ & SC & 4.5 & -5.7 & 24.4 & -0.4 \\
$1 / 29$ & FL & 2.7 & -1.2 & -3.1 & -0.5 \\
$2 / 5$ & Super Tuesday & 1.5 & 0.2 & - & 1.1 \\
$2 / 9$ & LA, NE, WA, VI & 2.1 & 0.3 & - & 2.5 \\
$2 / 10$ & ME & 2.0 & 5.5 & - & 2.4 \\
$2 / 12$ & DC, MD, VA & 1.6 & -2.9 & - & 1.3 \\
$2 / 19$ & HI, WI & 0.3 & 1.8 & - & -0.7 \\
$3 / 4$ & OH, RI, TX, VT & -3.0 & -0.5 & - & -2.6 \\
$3 / 8$ & WY & -2.6 & 2.2 & - & 0.0 \\
$3 / 11$ & MS & 1.9 & 2.0 & - & 0.4 \\
$4 / 22$ & PA & -0.8 & 5.5 & - & 0.3 \\
$5 / 3$ & Guam & 0.5 & 3.9 & - & 0.0 \\
$5 / 6$ & IN, NC & 2.7 & 9.3 & - & 0.6 \\
$5 / 13$ & WV & 0.1 & -1.4 & - & 0.4 \\
$5 / 20$ & KY, OR & -0.2 & 9.9 & - & -0.4 \\
6/1 & PR & 2.0 & -1.4 & - & 0.1 \\
\hline Note: Super Tuesday states include AK, AL, AZ, AR, CA, CO, CT, DE, GA, ID, IL, \\
KS, MA, MN, MO, NJ, NM, NY, ND, OK, TN, UT. "Democrat” refers to change in \\
price of contract of Democrat winning presidency. & &
\end{tabular}


Table 2: Changes in Probabilities of Winning General Election

Conditional on Winning the Nomination (Republicans)

\begin{tabular}{|c|c|c|c|c|c|}
\hline Date & States & McCain & Huckabee & Romney & Republican \\
\hline $1 / 3$ & IA & $4.5 \%$ & $-3.2 \%$ & $5.1 \%$ & $-0.1 \%$ \\
\hline $1 / 5$ & WY & -2.2 & -3.9 & -0.3 & -1.1 \\
\hline $1 / 8$ & $\mathrm{NH}$ & 0.8 & -3.7 & 2.2 & -0.3 \\
\hline $1 / 15$ & MI & 0.5 & 0.3 & -0.3 & -0.4 \\
\hline $1 / 19$ & $\mathrm{NV}, \mathrm{SC}$ & -2.7 & 5.5 & 2.7 & 0.5 \\
\hline $1 / 29$ & $\mathrm{FL}$ & 0.0 & 14.8 & 6.0 & 1.5 \\
\hline $2 / 1$ & $\mathrm{ME}$ & -0.7 & -2.8 & 4.6 & 0.2 \\
\hline $2 / 5$ & Super Tuesday & -0.8 & -13.8 & 22.3 & -1.1 \\
\hline $2 / 9$ & $\mathrm{LA}, \mathrm{KS}$ & -2.3 & 4.1 & 一 & -1.1 \\
\hline $2 / 12$ & $\mathrm{DC}, \mathrm{MD}, \mathrm{VA}$ & -0.9 & -4.4 & $\longrightarrow$ & -0.9 \\
\hline $2 / 19$ & WA, WI & 0.0 & 1.4 & $\longrightarrow$ & 0.2 \\
\hline $2 / 23$ & AS, NMI & 0.8 & -1.2 & - & 0.3 \\
\hline $2 / 24$ & PR & 0.6 & -1.9 & - & 0.2 \\
\hline $3 / 4$ & $\mathrm{OH}, \mathrm{RI}, \mathrm{TX}, \mathrm{VT}$ & 1.0 & -7.8 & - & 2.1 \\
\hline $3 / 8$ & Guam & 0.3 & - & - & -0.1 \\
\hline $3 / 11$ & MS & -0.4 & $\longrightarrow$ & - & -0.2 \\
\hline $4 / 5$ & VI & 0.1 & $\longrightarrow$ & - & 0.1 \\
\hline $4 / 22$ & PA & -0.4 & - & - & -0.4 \\
\hline $5 / 6$ & $\mathrm{IN}, \mathrm{NC}$ & -1.0 & $\longrightarrow$ & - & -0.4 \\
\hline $5 / 13$ & WV, NE & 0.6 & - & $\longrightarrow$ & -0.2 \\
\hline $5 / 20$ & $\mathrm{KY}, \mathrm{OR}$ & 0.8 & $\longrightarrow$ & $\longrightarrow$ & 0.8 \\
\hline $5 / 27$ & ID & 0.1 & $\square$ & - & -0.4 \\
\hline
\end{tabular}


Table 3: Changes in Nomination Contracts (Democrats)

\begin{tabular}{|c|c|c|c|c|c|c|c|c|}
\hline Date & $\underline{\text { States }}$ & $\begin{array}{l}\text { Obama } \\
\text { Absolute }\end{array}$ & $\frac{\text { Obama }}{\underline{\%}}$ & $\begin{array}{l}\text { Clinton } \\
\underline{\text { Absolute }}\end{array}$ & Clinton \% & $\frac{\text { Obama }}{\text { Abs. (Adj.) }}$ & $\begin{array}{l}\text { Clinton } \\
\text { Abs. (Adj.) }\end{array}$ & Delegates \\
\hline $1 / 3$ & IA & 18.6 & 69.9 & -13.2 & -20.3 & 40.5 & 39.2 & 45 \\
\hline $1 / 8$ & $\mathrm{NH}$ & -27.0 & -41.0 & 26.9 & 83.5 & 29.4 & 29.6 & 22 \\
\hline $1 / 15$ & MI & -2.1 & -5.1 & 1.6 & 2.7 & - & $\longrightarrow$ & 64 \\
\hline $1 / 19$ & NV & -8.6 & -21.3 & 8.3 & 14.4 & 18.6 & 18.7 & 25 \\
\hline $1 / 26$ & $\mathrm{SC}$ & 4.5 & 14.1 & -4.2 & -6.3 & 56.2 & 51.5 & 45 \\
\hline $1 / 29$ & $\mathrm{FL}$ & -0.4 & -1.0 & 0.9 & 1.5 & - & 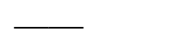 & 92.5 \\
\hline $2 / 5$ & Super Tuesday & 4.8 & 10.5 & -4.9 & -9.0 & 64.1 & 71.0 & 1681 \\
\hline $2 / 9$ & LA, NE, WA & 8.9 & 15.6 & -8.4 & -19.8 & 86.6 & 74.8 & 161 \\
\hline $2 / 10$ & $\mathrm{ME}$ & 11.1 & 18.8 & -10.9 & -26.8 & - & - & 24 \\
\hline $2 / 12$ & $\mathrm{DC}, \mathrm{MD}, \mathrm{VA}$ & 3.6 & 5.1 & -3.5 & -11.8 & - & - & 168 \\
\hline $2 / 19$ & HI, WI & 7.2 & 10.0 & -7.9 & -28.0 & 55.6 & 56.0 & 94 \\
\hline $3 / 4$ & OH, RI, TX, VT & -11.7 & -13.8 & 11.8 & 79.5 & 24.6 & 24.8 & 370 \\
\hline $3 / 8$ & WY & 2.9 & 3.9 & -3.6 & -13.1 & 66.4 & 53.6 & 12 \\
\hline $3 / 11$ & MS & 0.5 & 0.7 & 0.7 & 2.9 & 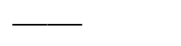 & - & 33 \\
\hline $4 / 22$ & PA & -2.4 & -2.9 & 2.7 & 18.2 & 16.8 & 18.0 & 158 \\
\hline $5 / 6$ & $\mathrm{IN}, \mathrm{NC}$ & 13.3 & 17.6 & -11.8 & -54.0 & — & - & 187 \\
\hline $5 / 13$ & WV & 0.8 & 0.9 & -0.7 & -7.6 & -3.8 & -3.3 & 28 \\
\hline $5 / 20$ & $\mathrm{KY}, \mathrm{OR}$ & 0.2 & 0.2 & 0.2 & 3.8 & - & - & 103 \\
\hline $6 / 3$ & $\mathrm{MT}, \mathrm{SD}$ & 2.8 & 3.0 & -2.6 & -37.0 & 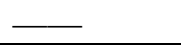 & $\overline{ }$ & 31 \\
\hline
\end{tabular}

Note: Super Tuesday states include AK, AL, AZ, AR, CA, CO, CT, DE, GA, ID, IL, KS, MA, MN, MO, NJ, NM, NY, ND, OK, TN, UT. 
Table 4: Changes in Nomination Contracts (Republicans)

\begin{tabular}{|c|c|c|c|c|c|}
\hline Date & $\underline{\text { States }}$ & $\begin{array}{l}\text { McCain } \\
\text { Absolute }\end{array}$ & $\frac{\text { McCain }}{\%}$ & $\frac{\text { McCain }}{\text { Abs. (Adj.) }}$ & Delegates \\
\hline $1 / 3$ & IA & 9.1 & 38.8 & - & 37 \\
\hline $1 / 5$ & WY & 1.2 & 3.6 & 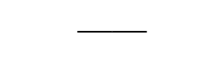 & 14 \\
\hline $1 / 8$ & $\mathrm{NH}$ & 1.5 & 4.2 & 8.7 & 12 \\
\hline $1 / 15$ & MI & -7.1 & -16.4 & 13.0 & 30 \\
\hline $1 / 19$ & $\mathrm{NV}, \mathrm{SC}$ & 14.3 & 36.4 & 134.0 & 55 \\
\hline $1 / 29$ & FL & 25.5 & 44.1 & 50.7 & 57 \\
\hline $2 / 1$ & $\mathrm{ME}$ & 3.1 & 3.7 & - & 18 \\
\hline $2 / 5$ & Super Tuesday & 4.8 & 5.5 & -45.5 & 1059 \\
\hline $2 / 9$ & LA, KS & -1.4 & -1.5 & 1.9 & 80 \\
\hline $2 / 12$ & $\mathrm{DC}, \mathrm{MD}, \mathrm{VA}$ & 1.2 & 1.3 & 21.8 & 113 \\
\hline $2 / 19$ & WA, WI & 0.1 & 0.1 & 1.1 & 77 \\
\hline $3 / 4$ & $\mathrm{OH}, \mathrm{RI}, \mathrm{TX}, \mathrm{VT}$ & 2.1 & 2.3 & & 256 \\
\hline $3 / 11$ & MS & 0.1 & 0.1 & $\longrightarrow$ & 36 \\
\hline $4 / 22$ & PA & -0.1 & -0.1 & - & 71 \\
\hline $5 / 6$ & IN, NC & -1.0 & -1.1 & $\longrightarrow$ & 123 \\
\hline $5 / 13$ & $\mathrm{NE}$ & -0.2 & -0.1 & $\longrightarrow$ & 33 \\
\hline $5 / 20$ & KY, OR & 0.1 & 0.1 & - & 75 \\
\hline $5 / 27$ & ID & -0.1 & -0.1 & - & 32 \\
\hline $6 / 3$ & NM, SD & 0.1 & 0.1 & $\longrightarrow$ & 53 \\
\hline
\end{tabular}


Figure 1: Influence of State Nominating Contests (Democrats)

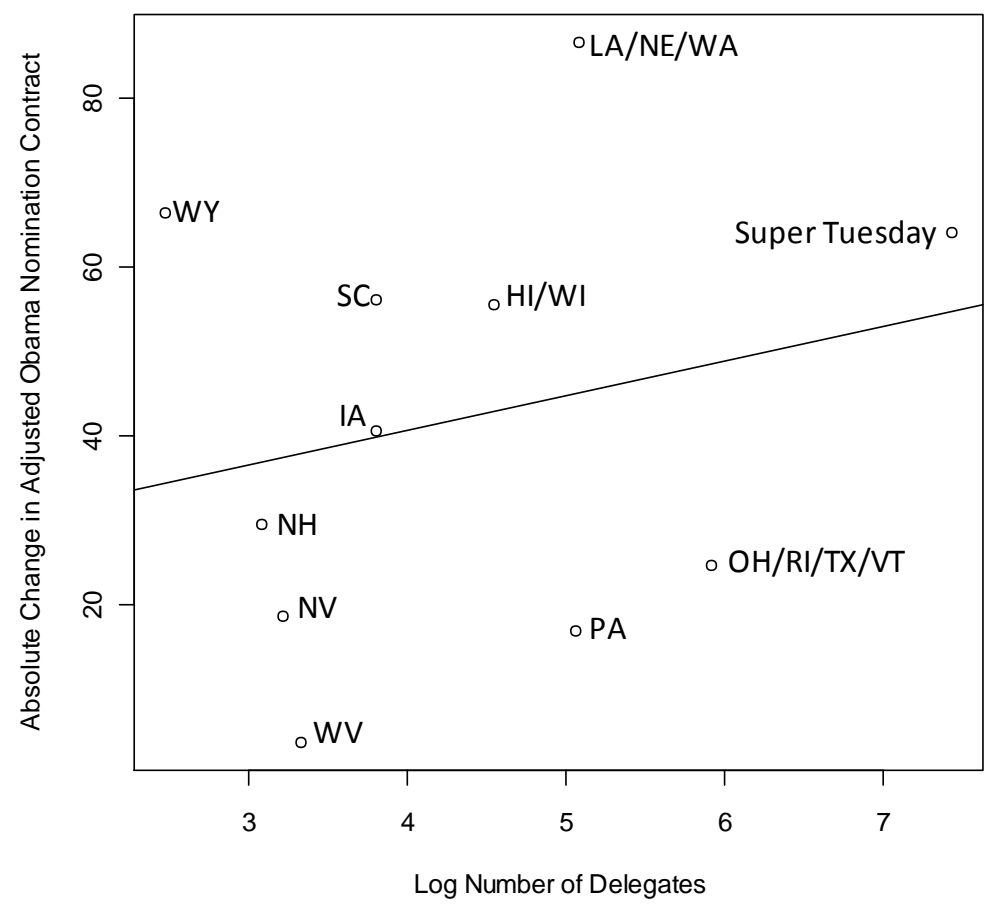

$\Delta$ Contract $=24.06+4.14 * \ln ($ Delegates $)$

(26.15) (5.74) 
Figure 2: Influence of State Nominating Contests (Republicans)

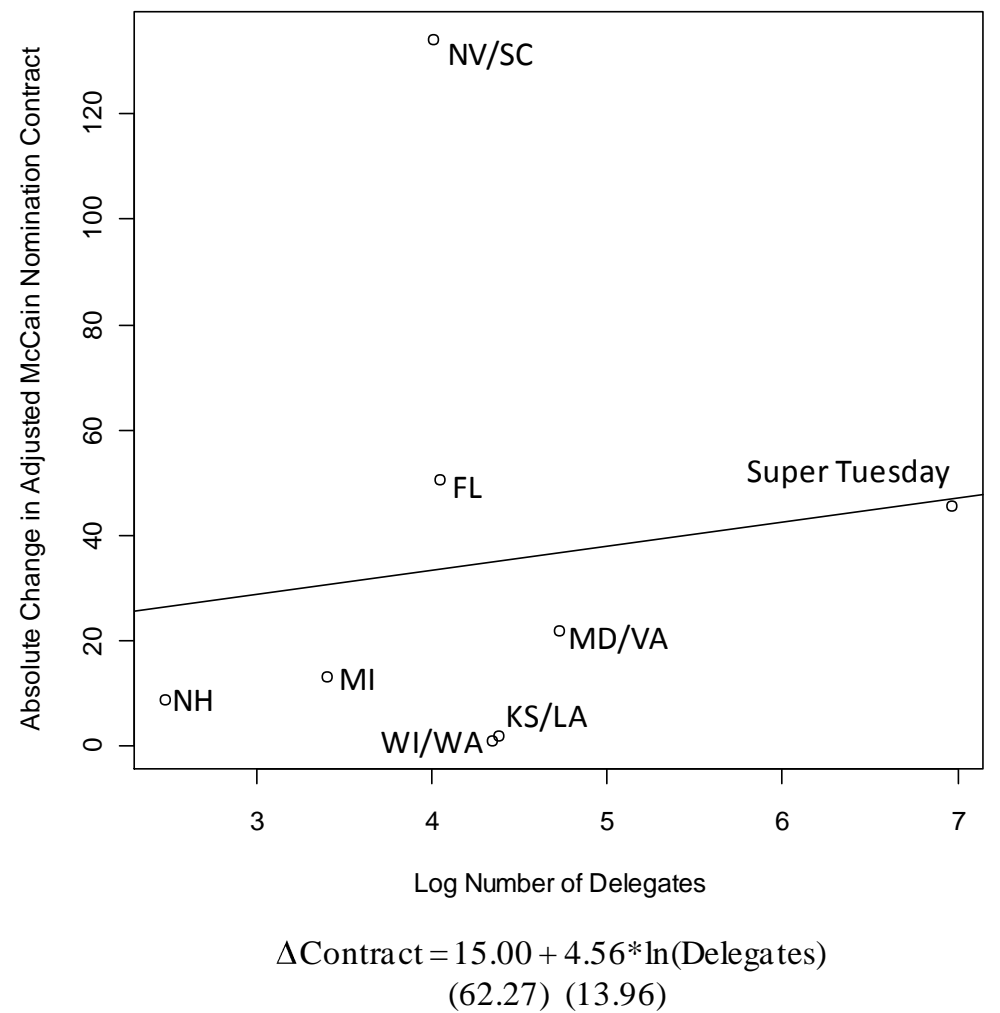

